\title{
GaN-based 1-MHz Partial Parallel Dual Active Bridge Converter with Integrated Magnetics
}

Zhang, Zhe; Huang, Jiasheng ; Xiao, Yudi

Published in:

I E E E Transactions on Industrial Electronics

Link to article, DOI:

10.1109/TIE.2020.3007078

Publication date:

2021

Document Version

Peer reviewed version

Link back to DTU Orbit

Citation (APA):

Zhang, Z., Huang, J., \& Xiao, Y. (2021). GaN-based 1-MHz Partial Parallel Dual Active Bridge Converter with Integrated Magnetics. I E E E Transactions on Industrial Electronics, 68(8), 6729-6738.

https://doi.org/10.1109/TIE.2020.3007078

\section{General rights}

Copyright and moral rights for the publications made accessible in the public portal are retained by the authors and/or other copyright owners and it is a condition of accessing publications that users recognise and abide by the legal requirements associated with these rights.

- Users may download and print one copy of any publication from the public portal for the purpose of private study or research.

- You may not further distribute the material or use it for any profit-making activity or commercial gain

- You may freely distribute the URL identifying the publication in the public portal

If you believe that this document breaches copyright please contact us providing details, and we will remove access to the work immediately and investigate your claim. 


\title{
GaN-based 1-MHz Partial Parallel Dual Active Bridge Converter with Integrated Magnetics
}

\author{
Zhe Zhang, Senior Member, IEEE, Jiasheng Huang, Yudi Xiao, Student Member, IEEE
}

\begin{abstract}
In this paper, a partial parallel dual active bridge (PPDAB) converter is proposed to lower the current stress over the switching devices on the low-voltage (LV) side. Gallium Nitride ( $\mathrm{GaN}$ ) transistors are used to improve efficiency and power density at $1 \mathrm{MHz}$ switching frequency. Moreover, in order to reduce the number of magnetic components and achieve more compact design, with a unique three-leg core geometry, a new method of integrating three transformers and their associated interfacing inductors is proposed. The integration is able to shorten winding length and therefore reduces winding dc resistance. Moreover, wounding the secondary windings on each outer leg in the core enlarges leakage inductance, which can serve as the interfacing inductor $L_{a c}$ in the PPDAB converter. Given that, a reluctance model to analyze coupling effect of the secondary windings as well as their current balance is derived and validated by finite element simulations. Based on both calculations and simulations, the proposed integrated transformer is found to be functionally equivalent to three discrete transformers, in which their primary windings are connected in series, and the additional $L_{a c}$ inductor. Additionally, given the same number of the turns of the windings in each parallel module, the ac currents in these three secondary windings can inherently balance. Finally, a fully GaN-based 1.2-kW $1-\mathrm{MHz} 400 \mathrm{~V} / 50 \mathrm{~V}$ prototype with a peak efficiency of $97.51 \%$ is built and tested to verify the theoretical analysis.
\end{abstract}

Index Terms-Gallium Nitride (GaN), high frequency, dual active bridge (DAB), partial parallel, magnetic integration.

\section{NOMENCLATURE}

$\bar{I} \quad$ Average current of $L_{a c}$ in a half period.

$\Delta B_{\text {recommend }}$ The recommended value of $\Delta B$.

$\delta_{\text {pri }}, \delta_{\text {sec }}$ Insulation distance between core and primary windings, core and secondary windings, respectively.

$\mathcal{R}_{a}, \mathcal{R}_{b}, \mathcal{R}_{c}$ Reluctance of the three outer legs, respectively.

$\mathcal{R}_{p} \quad$ Reluctance of the center leg.

$\sigma_{\text {pri }}, \sigma_{\text {sec }}$ Distance between two adjacent turns of the primary winding, secondary winding, respectively.

$\varphi \quad$ Additional phase-shift angle as a percentage of the switching period.

$\varphi_{p x}(x=1,2)$ Additional phase-shift angle as a percentage of the switching period.

Manuscript received January 29, 2020; revised May 13, 2020; accepted June 10, 2020. (Corresponding author: Zhe Zhang)

Z. Zhang and Y. Xiao are with the Department of Electrical Engineering, Technical University of Denmark, 2800 Kgs. Lyngby, Denmark (email: zz@elektro.dtu.dk; yudxiao@elektro.dtu.dk).

J. Huang is with the School of Electrical Engineering, Xi'an Jiaotong University, Xi'an 710049, China (e-mail: hjs0118@outlook.com). $a, b \quad$ Length and width of the cross-sectional area of the outer legs.

$f_{s}, T_{s} \quad$ Switching frequency, switching period.

$h_{\text {copper }}$ Thickness of the copper.

$h_{P C B}$ Thickness of the PCBs.

$h_{\text {window }}, w_{\text {window }}$ Height and width of the core window.

$i_{L_{a c}}\left(t_{x}\right)(x=1-4)$ Instantaneous current value of the $L_{a c}$.

$I_{P r i}, I_{S e c}$ Primary and secondary current excitation RMS value in FEA.

$i_{x}(x=a, b, c, p)$ Current of the three secondary windings and primary winding.

$j \quad$ Electric current density.

$L_{a c} \quad$ Inductance of the ac inductor.

$m_{\text {pri }}, m_{\text {sec }}$ Number of primary and secondary windings in parallel

$n \quad$ Turn ratio of the transformer.

$n_{P C B}$ Number of the PCBs of the windings.

$n_{\text {pri }}, n_{\text {sec }}$ Number of turns of the primary and secondary windings in one layer.

$N_{x}(x=a, b, c, p)$ Number of turns of the three secondary windings and primary winding.

$P \quad$ Transmission power.

$r \quad$ Radius of the center leg.

$V_{\text {in }}, V_{\text {out }}$ Input voltage, output voltage.

$w_{\text {pri }}, w_{\text {sec }}$ Width of the primary and secondary windings.

\section{INTRODUCTION}

$\mathbf{O}$ VETR the past few years, renewable energies have experienced a rapid development due to the global awareness on limited fossil fuel resources and widespread sensibility towards the environmental issues. As shown in Fig. 1, energy storage systems (ESSs) are widely used in dc micro grid as it is a critical part of the solution to address the intermittency and unpredictable production of the renewable energy. Therefore, as the interface between battery and dc-bus, bidirectional dcdc converters (BDCs) have received increasing attention [1][3]. The dual active bridge (DAB) converter is a promising topology as BDC in the ESS, due to its unique features such as symmetric structure and zero voltage switching (ZVS) [4][9].

In recent years, there is intensive research on improving DAB converters' efficiency, power density and reliability by using new modulation schemes, new devices and new system interconnection configurations [8]-[21]. For bidirectional dcdc converters with high voltage gain, the power devices on the low-voltage (LV) side require more consideration due to the 


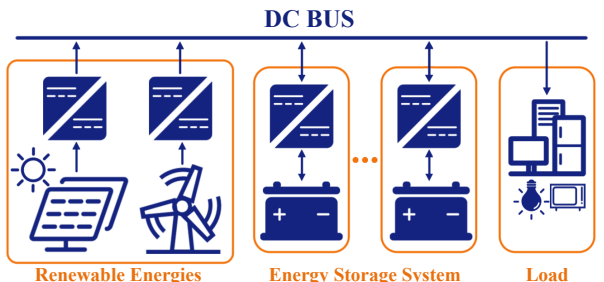

Fig. 1. DC microgrid system.

current stress, especially in high-power applications. Therefore, paralleling semiconductor devices or converter modular units (CMUs) are usually applied to increase converter reliability. In [15], paralleling four switching devices are employed to reduce the current stress and conduction loss on the devices and increase the power capability of the converter, a peak efficiency of $98.8 \%$ is achieved, on the other hand, paralleling semiconductor devices complicates circuit layout and increases parasitic inductance in high-frequency switching loops [22]. In order to reduce the current stress and simplify the layout, paralleling CMUs is adopted in [9], [16]-[19]. In [20], the structure shown in Fig. 2 (a) was adopted, the windings of the parallel CMUs are fully coupled through a magnetic core. The fully coupled windings give a path for circulating current when the characteristics of the parallel CMUs are different or the gate signals of the corresponding switches are asynchronous, thereby an additional control scheme is required to eliminate circulating current between the parallel units. To avoid the circulating current, [9] and [21] proposed another structure of paralleling CMUs, as shown in Fig. 2 (b). The windings of units are wounded around discrete cores separately. Due to the series connection of windings on the high-voltage (HV) side, the ac currents of CMUs are forced to be the same. In addition, the decoupled secondary windings provide opportunities for adding a phase shift between the units which gives an additional degree of freedom for power control. In [9], the phase shift between the parallel units can reduce the reactive power and improve the converter efficiency. In [21], a multilevel high-frequency-link dc transformer based on dual active phase-shift principle is proposed. The medium-voltage dc (MVDC) interface employs single phase modular multilevel converter. The low-voltage dc (LVDC) interface is composed of several full-bridges. Based on the phase-shift modulation both in the MVDC and LVDC side, the converter achieves higher power factor.

Furthermore, besides efficiency improvement, the emerging wide-band-gap (WBG) devices, such as Silicon Carbide (SiC) and Gallium Nitride $(\mathrm{GaN})$ provide the enabling technology to increase the switching frequency to megahertz [23]-[28]. One benefit of high-frequency operation is that the volume of passive components, such as transformers, inductors and capacitors can be significantly reduced. (e.g., for the DAB converter, the value of the $L_{a c}$ decreases along with the increase of the switching frequency for the same transmission power). Thus, with optimal design, the parasitic components of the transformer can be employed as the passive components in the topology, thereby the external inductors or capacitors

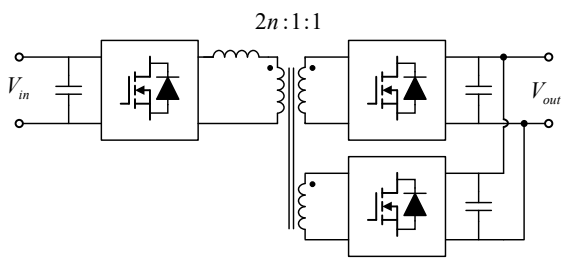

(a)

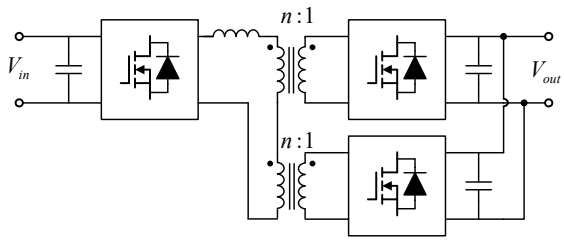

(b)

Fig. 2. Two solutions of paralleling CMUs.(a) Parallel CMUs with one transformer. (b) Parallel CMUs with two discrete transformers.

can be eliminated which can further improve power density of the converter. In [26], the proposed topology makes full use of the parasitic components of the transformer. Without adding the additional LC branch, the switching impedance is optimized according to the inductive components of the transformer. The work presented in [27] proposed a CLCL resonant DC/DC converter based on the transformer leakage inductance. With the adoption of the leakage inductor, the volume of the converter can be greatly reduced. In [28], an integrated transformer with a controllable leakage inductance was proposed. The leakage inductor replace the external inductor to serve as the resonant inductor for the LLC converter which can reduce the number of magnetic components and increase the power density of the converter. [29] presents modeling, design and analysis of three-limb high frequency transformer for $\mathrm{SiC}$ based three-port $\mathrm{DAB}$

In this paper, a partial parallel dual active bridge (PPDAB) converter is adopted for its features on current balancing and flexible controllability. In order to reduce the number of magnetic components, a new integrated magnetic structure with a unique three-leg core geometry and its associated winding arrangement is proposed. Compared to the discrete solutions, the proposed transformer reduces the length of the primary windings, magnetically decouples the three secondary windings, enlarges leakage inductance and thereby need no extra interfacing ac inductors, and at the same time keeps the capability of inherent high frequency ac current balancing.

The paper is organized as follows. Section II analyzes the operation of the PPDAB converter with three parallel LV Hbridge modules. Section III introduces the magnetic integration approach, and compares the proposed integrated transformers with the discrete solutions. Moreover, the reluctance models and the design flowchart are also provided. In Section IV, a $1.2-\mathrm{kW} 1-\mathrm{MHz} 400 \mathrm{~V} / 50 \mathrm{~V}$ GaN-based prototype was built to verify the operation of the PPDAB converter with the new proposed integrated transformers. Finally, conclusions and discussions are presented in Section V. 


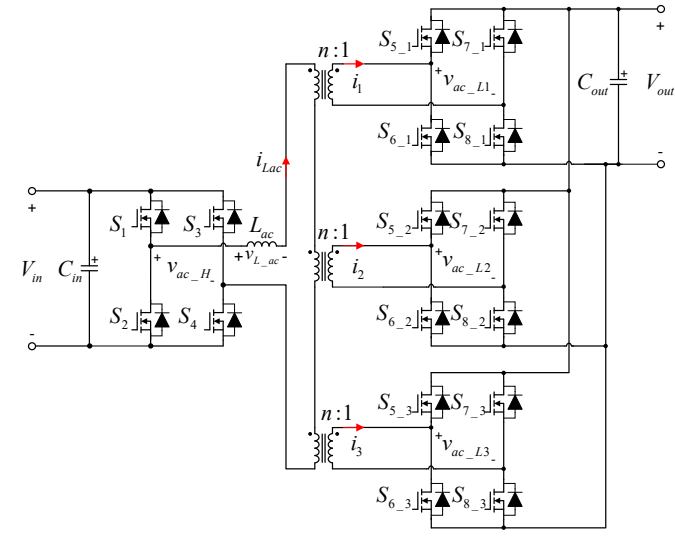

Fig. 3. Topology of the PPDAB converter.

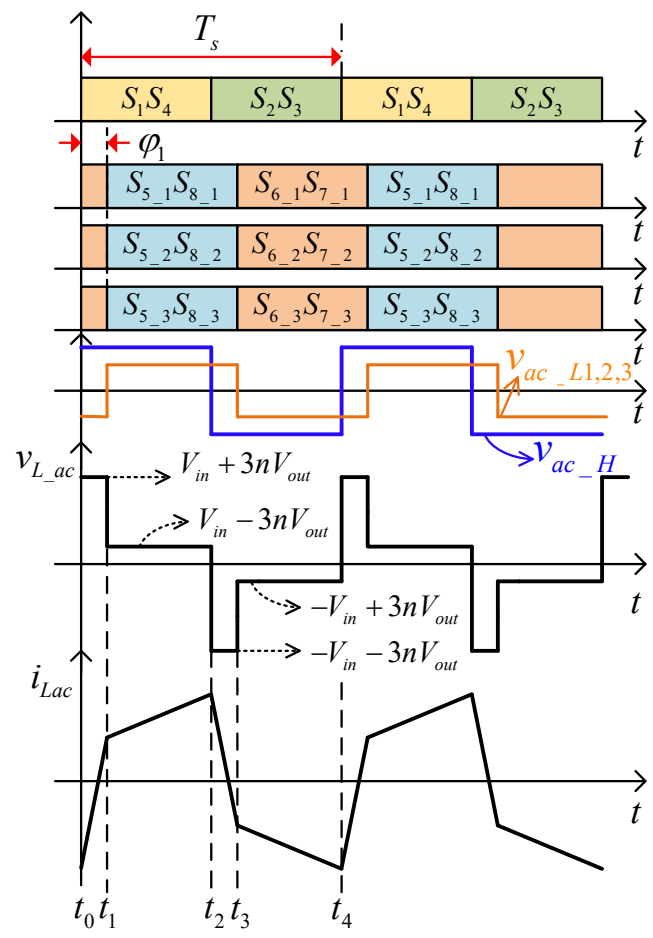

Fig. 4. A typical waveform of the PPDAB converter with SPS control.

\section{Partial parallel dual active bridge DC/DC CONVERTER}

In order to reduce LV side current stress further and achieve high power, base on the structure shown in Fig. 2 (b), a PPDAB converter with three paralleled LV H-bridges as shown in Fig. 3 is presented in this paper. The control strategies for the DAB converter including single-phase-shift (SPS), extended-phase-shift (EPS), dual-phase-shift (DPS) and triplephase-shift (TPS) control are also suitable for the PPDAB converter. The SPS control is adopted in this paper due to its advantages, such as simple control strategy and high dynamic. The typical waveform of the PPDAB converter with SPS control $(\varphi \leq 0.5)$ is shown in Fig. 4. Based on the following assumptions, the converter's steady-state equations can be derived.

1) All the switches are ideal.
2) $V_{\text {in }}$ and $V_{\text {out }}$ are constant.

$\left[t_{0}, t_{1}\right]$ : in this subinterval, the voltage across the $L_{a c}$ is $V_{\text {in }}+3 n V_{\text {out }}$. The $L_{a c}$ current increases linearly.

$$
i_{L_{a c}}\left(t_{1}\right)=i_{L_{a c}}\left(t_{0}\right)+\frac{V_{\text {in }}+3 n V_{\text {out }}}{L_{a c}} \cdot \varphi \cdot T_{s}
$$

$\left[t_{1}, t_{2}\right]$ : in this subinterval, the voltage across the $L_{a c}$ is $V_{\text {in }}-3 n V_{\text {out }}$.

$$
i_{L_{a c}}\left(t_{2}\right)=i_{L_{a c}}\left(t_{1}\right)+\frac{V_{\text {in }}-3 n V_{\text {out }}}{L_{a c}} \cdot\left(\frac{1}{2}-\varphi\right) \cdot T_{s}
$$

Similarly, $i_{L_{a c}}\left(t_{3}\right)$ and $i_{L_{a c}}\left(t_{4}\right)$ can be expressed in (3) and (4).

$$
i_{L_{a c}}\left(t_{3}\right)=i_{L_{a c}}\left(t_{2}\right)-\frac{V_{i n}+3 n V_{o u t}}{L_{a c}} \cdot \varphi \cdot T_{s}
$$

$$
i_{L_{a c}}\left(t_{4}\right)=i_{L_{a c}}\left(t_{3}\right)+\frac{-V_{\text {in }}+3 n V_{\text {out }}}{L_{a c}} \cdot\left(\frac{1}{2}-\varphi\right) \cdot T_{s}
$$

Due to the symmetry of the ac inductor current, $i_{L_{a c}}\left(t_{0}\right)=$ $-i_{L_{a c}}\left(t_{2}\right)$. So $i_{L_{a c}}\left(t_{0}\right)$ can be derived.

$$
i_{L_{a c}}\left(t_{0}\right)=-\frac{V_{\text {in }}+3 n V_{\text {out }} \cdot(4 \varphi-1)}{4 L_{a c}} \cdot T_{s}
$$

The average current of $L_{a c}$ in a half period is expressed in (6).

$$
\begin{aligned}
\bar{I} & =\left[i_{L_{a c}}\left(t_{0}\right)+i_{L_{a c}}\left(t_{1}\right)\right] \cdot \varphi+\left[i_{L_{a c}}\left(t_{1}\right)+i_{L_{a c}}\left(t_{2}\right)\right] \cdot\left(\frac{1}{2}-\varphi\right) . \\
& =\frac{3 n V_{o u t}}{L_{a c}} \cdot \varphi(1-2 \varphi) \cdot T_{s}
\end{aligned}
$$

Hence, the steady-state power equation of the proposed three-phase PPDAB converter can be calculated,

$$
P=V_{\text {in }} \cdot \bar{I}=\frac{3 n V_{\text {in }} V_{\text {out }}}{f_{s} L_{a c}} \cdot \varphi \cdot(1-2 \varphi)
$$

\section{INTEGRATED THREE-PHASE HIGH-FREQUENCY TRANSFORMER}

\section{A. Integration}

When employing the PPDAB converter, the number of transformers increases. In this paper, new integrated transformers are proposed. The derivation process of the proposed magnetic integration is depicted in Fig. 5. The original three discrete transformers are shown in Fig. 5 (a), the three primary windings are in series connection. After the integration of the primary windings, the transformer as shown in Fig. 5 (b) can be obtained. The flux linkages of primary winding increase three times, so the total turns of the primary winding decrease by three times according to Faraday's law, with the reduction in the total length of the primary windings. Moreover, the primary windings can be placed in one layer to simplify the PCB layout. Then rotate three discrete cores and separate them by 120 degrees, as shown in Fig. 5(c). Finally, integrate three 120-degree leg sectors into one round center leg, as shown in Fig. 5 (d). The cross-sectional area of the center leg is equal to the sum area of the three outer legs for ensuring the same flux density along the flux paths, i.e.,

$$
s=\pi r^{2}=3 a b .
$$




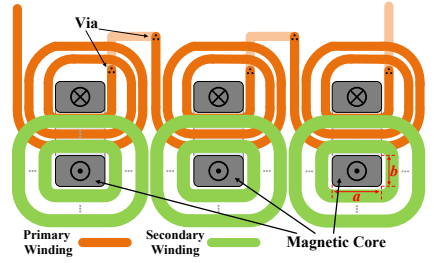

(a)

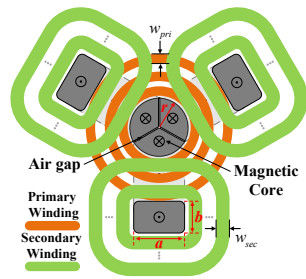

(c) (d)

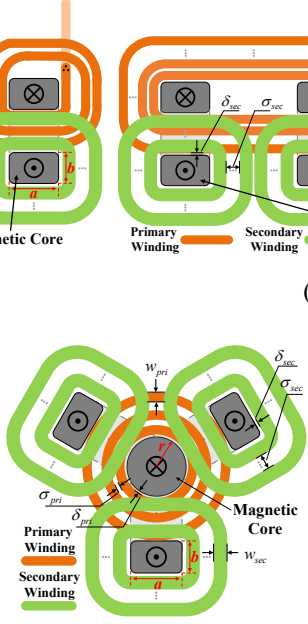

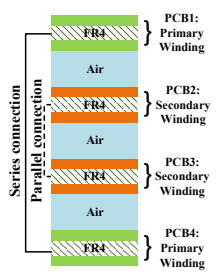

(e)
Fig. 5. Integrated magnetic structure for PPDAB converter.(a) Before integration. (b) After winding integration. (c) Rotate three discrete cores. (d) After core integration. (e) Stacking structure of the PCB windings.

TABLE I

PARAMETERS OF THE FEA SiMULATION

\begin{tabular}{cccc}
\hline \hline Parameter & Value & Parameter & Value \\
\hline$r$ & $10.70 \mathrm{~mm}$ & $f_{s}$ & $1 \mathrm{MHz}$ \\
$a$ & $18.53 \mathrm{~mm}$ & $I_{\text {pri }}$ & $3 \mathrm{~A}$ \\
$b$ & $6.40 \mathrm{~mm}$ & $I_{S e c}$ & $8 \mathrm{~A}$ \\
$w_{\text {pri }}$ & $4.25 \mathrm{~mm}$ & $h_{\text {window }}$ & $11.6 \mathrm{~mm}$ \\
$w_{\text {sec }}$ & $6.00 \mathrm{~mm}$ & $w_{\text {window }}$ & $20 \mathrm{~mm}$ \\
$h_{\text {copper }}$ & $70 \mu \mathrm{m}$ & Turns $-p, a, b, c$ & $8: 3: 3: 3$ \\
$\delta_{\text {pri }}$ & $0.5 \mathrm{~mm}$ & $\delta_{\text {sec }}$ & $0.254 \mathrm{~mm}$ \\
$\sigma_{\text {pri }}$ & $0.254 \mathrm{~mm}$ & $\sigma_{\text {sec }}$ & $0.254 \mathrm{~mm}$ \\
\hline \hline
\end{tabular}

The mean lengths of the primary windings in two different core structures as shown in Fig. 5 (b) and Fig. 5 (d) can be expressed in (9) and (10), respectively.

$$
\begin{gathered}
l_{\text {discrete }}=m_{\text {pri }}\left[n_{\text {pri }} \cdot(6 a+2 b+4 d)+n_{\text {pri }} \cdot 2 \pi\left(\delta_{\text {pri }}+\right.\right. \\
\left.\left.\frac{w_{\text {pri }}}{2}\right)+\sum_{q=0}^{n_{\text {pri }}-1} q \cdot 2 \pi\left(\sigma_{\text {pri }}+w_{\text {pri }}\right)\right] \\
l_{\text {integrated }}=m_{\text {pri }}\left[n_{\text {pri }} \cdot 2 \pi r+n_{\text {pri }} \cdot 2 \pi\left(\delta_{\text {pri }}+\frac{w_{\text {pri }}}{2}\right)\right. \\
\left.+\sum_{q=0}^{n_{\text {pri }}-1} q \cdot 2 \pi\left(\sigma_{\text {pri }}+w_{\text {pri }}\right)\right] \\
6 a+2 b+4 d>6 a+2 b \geq 2 \sqrt{12 a b}=4 \sqrt{\pi} \cdot r>2 \pi \cdot r
\end{gathered}
$$

Combine (8), (9), (10) and (11), it can be concluded that the mean length of windings is further reduced with core integration, therefore for the same copper thickness and winding width, winding dc resistance can be reduced. Nevertheless, for the ac winding loss, only the loss of the winding inside the core window can be calculated based on Dowell's equations [30]. Therefore, the finite element analysis (FEA) is used to
TABLE II

COMPARISON OF DIFFERENT TYPES OF TRANSFORMERS

\begin{tabular}{ccccc}
\hline \hline Solutions & Core type & Winding structure & Leakage inductance & Winding loss \\
\hline (a) & Proposed core & 1 Primary winding & $\mathbf{1 0 . 3 0 3} \mu \mathrm{H}$ & $\mathbf{2 . 7 0 7 7} \mathrm{W}$ \\
(b) & Proposed core & 3 Primary winding & $1.079 \mu \mathrm{H}$ & $\mathbf{2 . 7 2 9 0 W}$ \\
(c) & Three EI cores & 1 Primary winding & $1.974 \mu \mathrm{H}$ & $5.2213 \mathrm{~W}$ \\
(d) & Three EI cores & 3 Primary winding & $1.088 \mu \mathrm{H}$ & $\mathbf{2 . 7 4 2 9} \mathrm{W}$ \\
(e) & Three UI cores & 1 Primary winding & $1.968 \mu \mathrm{H}$ & $5.2178 \mathrm{~W}$ \\
(f) & Three UI cores & 1 Primary winding & $\mathbf{1 3 . 3 1 5 \mu \mathrm { H }}$ & $3.7987 \mathrm{~W}$ \\
(g) & Three UI cores & 3 Primary winding & $1.079 \mu \mathrm{H}$ & $\mathbf{2 . 7 3 1 4 W}$ \\
(h) & Three UI cores & 3 Primary winding & $\mathbf{1 3 . 5 7 4 \mu \mathrm { H }}$ & $3.4245 \mathrm{~W}$ \\
\hline \hline
\end{tabular}

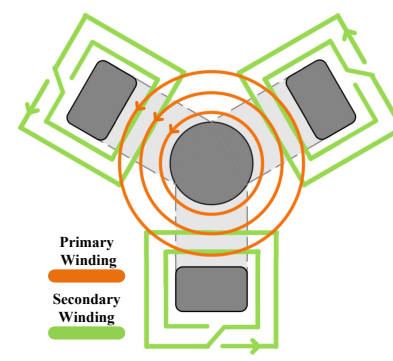

(a)

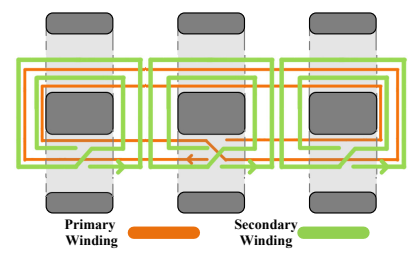

(c)

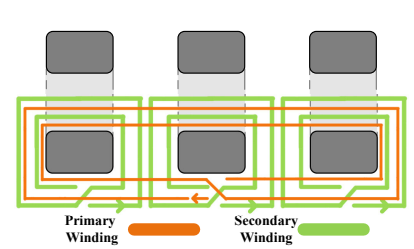

(e)

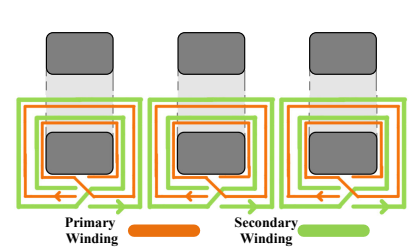

(g)

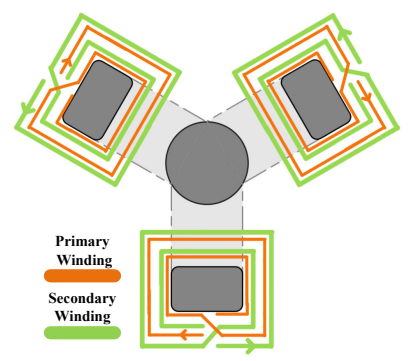

(b)

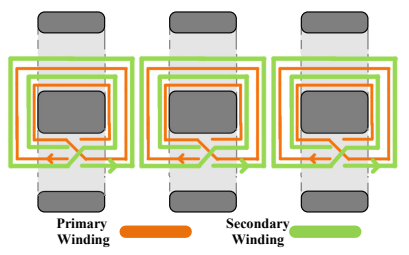

(d)

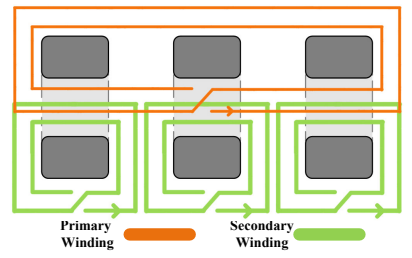

(f)

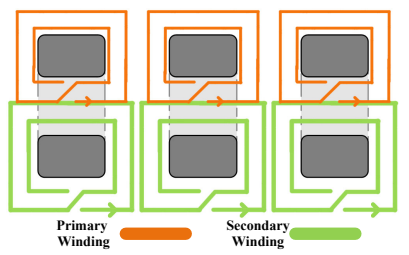

(h)
Fig. 6. Different transformer solutions. (a) Proposed core with one integrated primary winding. (b) Proposed core with three discrete primary windings. (c) Three El cores with one integrated primary winding. (d) Three El cores with three discrete primary windings. (e) Three UI cores with one integrated primary winding, the primary and secondary windings are fully overlapped. (f) Three UI cores with one integrated primary winding, the primary and secondary windings are partially overlapped. (g) Three UI cores with three discrete primary windings, the primary and secondary windings are fully overlapped. (h) Three UI cores with three discrete primary windings, the primary and secondary windings are partially overlapped.

assess the winding loss in this paper. The eight solutions are shown in Fig. 6, in which the arrows indicate current direction. 


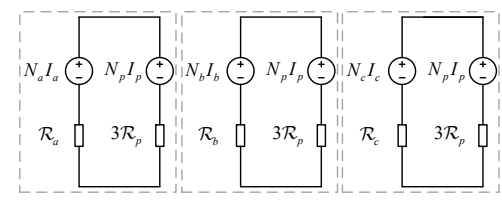

(a)

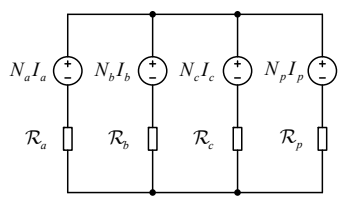

(b)
Fig. 7. Reluctance model. (a) Before core integration. (b) After core integration.

The proposed core geometry is used in the solutions (a) and (b), which have different primary winding layout. In (a), the primary winding is wound around the center leg, however, in (b), the primary winding is separated into three parts and placed on each of the three outer legs, respectively. It turns out that the coupling effect among the secondary windings is well weak and this feature will be analyzed in depth in Subsection II-B. The rest six solutions are traditional discrete transformers, so the secondary windings are totally decoupled. To make a fair comparison, the cross-sectional area, width and length of the core window, the width of winding are kept the same. And the PCB winding stacking structure is set as shown in Fig. 5(e). The parameters of the excitation, cores and windings dimensions are configured according to Table I. The FEA simulation results are listed in Table II. From this comparison, we can conclude that the solutions (a), (b), (d) and (g) have almost equal winding loss, but in solutions (b), (d) and $(\mathrm{g})$, the three discrete primary windings will complicate the layout and the connections will also induce extra loss. Moreover, the leakage inductors in solutions (a), (f) and (h) are large enough to serve as the ac inductor $L_{a c}$ in the PPDAB converter. Therefore, the solution (a) is selected for its lower winding loss and large leakage inductance.

\section{B. Coupling effect analysis}

1) Reluctance model: As mentioned before, three LV windings are integrated in the proposed transformer. In order to analyze the impact on circuit operations that caused by the coupling, a comparison between the integrated transformers, which shown in Fig. 5 (c) and Fig. 5 (d) is made. The reluctance models of these two structure are shown in Fig. 7. It is worth to note that before core integration, in Fig. 5 (c), three individual cores are separated by small air gaps, which results in the couplings between the LV windings are weak enough to be ignored. Therefore, the reluctance model is composed by three separate parts.

Due to the symmetrical structure, the following assumptions have been made to simplify the model without losing accuracy.

1) The turns of three LV windings are the same, $N_{a}=N_{b}=$ $N_{c}=N_{s}$.

2) The reluctances of three outer legs are the same, $\mathcal{R}_{a}=$ $\mathcal{R}_{b}=\mathcal{R}_{c}=\mathcal{R}_{s}$. (The reluctance can be calculated by $\mathcal{R}=l /(\mu s)$, where $l$ is the length of magnetic path , $\mu$ is magnetic material permeability and $s$ is cross-sectional area.)

3) The self-inductances of LV windings are the same, $L_{a}=$ $L_{b}=L_{c}=L_{s}$
TABLE III

EXPRESSION OF PARAMETER OF TWO TRANSFORMERS

\begin{tabular}{cccc}
\hline \hline \multicolumn{2}{c}{ Before core integration } & \multicolumn{2}{c}{ After core integration } \\
\hline$L_{m p}$ & $\frac{N_{p}{ }^{2}}{\mathcal{R}_{p}+\mathcal{R}_{s} / 3}$ & $L_{m p}^{\prime}$ & $\frac{N_{p}{ }^{2}}{\mathcal{R}_{p}+\mathcal{R}_{s} / 3}$ \\
$L_{m s}$ & $\frac{N_{s}{ }^{2}}{3 \mathcal{R}_{p}+\mathcal{R}_{s}}$ & $L_{m s}^{\prime}$ & $\frac{N_{s}{ }^{2}}{3 \mathcal{R}_{p}+\mathcal{R}_{s}} \cdot \frac{\mathcal{R}_{s}+2 \mathcal{R}_{p}}{\mathcal{R}_{s}}$ \\
$M_{p s}$ & $\frac{N_{p} N_{s}}{3 \mathcal{R}_{p}+\mathcal{R}_{s}}$ & $M_{p s}^{\prime}$ & $\frac{N_{p} N_{s}}{3 \mathcal{R}_{p}+\mathcal{R}_{s}}$ \\
$M_{s s}$ & 0 & $M_{s s}^{\prime}$ & $\frac{N_{s}{ }^{2}}{3 \mathcal{R}_{p}+\mathcal{R}_{s}} \cdot \frac{\mathcal{R}_{p}}{\mathcal{R}_{s}}$ \\
$L_{k p}, L_{k s}$ & & \multicolumn{2}{c}{ Remain unchanged } \\
\hline \hline
\end{tabular}

4) The magnetizing inductances of LV windings are the same, $L_{m a}=L_{m b}=L_{m c}=L_{m s}$.

5) The leakage inductances of the LV sides are the same, $L_{k a}=L_{k b}=L_{k c}=L_{k s}$.

6) The mutual inductances between the $\mathrm{HV}$ windings and $\mathrm{LV}$ windings are the same, $M_{p a}=M_{p b}=M_{p c}=M_{p s}$.

7) The mutual inductances between LV windings are the same, $M_{a b}=M_{a c}=M_{b c}=M_{s s}$.

According to the reluctance models, the parameters of these two cases can be calculated (see Table III). It can be concluded that after core integration, the magnetizing inductance of $\mathrm{HV}$ winding and mutual inductance between $\mathrm{HV}$ and $\mathrm{LV}$ windings keep constant, while magnetizing inductance of LV windings and mutual inductance between three LV windings increase. It can also be found that before core integration the magnetizing inductance of LV windings, $L_{m s}$ and mutual inductance between LV windings, $M_{s s}$ and those after core integration, $L_{m s}^{\prime}$ and $M_{s s}^{\prime}$ meet (12). Moreover, the leakage inductance almost remain unchanged that is validated by simulations in ANSYS.

$$
L_{m s}=L_{m s}^{\prime}-2 M_{s s}^{\prime}
$$

2) equivalent circuit: The equivalent circuit of the proposed integrated transformer is shown in Fig. 8. Then we can get (13), which is a general equation and valid for both before and after core integration.

$$
\mathbf{V}=\mathbf{L}\left(\mathbf{L}^{\prime}\right) \cdot \dot{\mathbf{I}}
$$

Where $\mathbf{V}=\left[\begin{array}{llll}v_{p} & v_{a} & v_{b} & v_{c}\end{array}\right]^{\mathrm{T}}, \mathbf{I}=\left[\begin{array}{llll}i_{p} & i_{a} & i_{b} & i_{c}\end{array}\right]^{\mathrm{T}}$,

$\mathbf{L}\left(\mathbf{L}^{\prime}\right)=\left[\begin{array}{cccc}L_{p}\left(L_{p}^{\prime}\right) & M_{p s}\left(M_{p s}^{\prime}\right) & M_{p s}\left(M_{p s}^{\prime}\right) & M_{p s}\left(M_{p s}^{\prime}\right) \\ M_{p s}\left(M_{p s}^{\prime}\right) & L_{s}\left(L_{s}^{\prime}\right) & 0\left(-M_{s s}^{\prime}\right) & 0\left(-M_{s s}^{\prime}\right) \\ M_{p s}\left(M_{p s}^{\prime}\right) & 0\left(-M_{s s}^{\prime}\right) & L_{s}\left(L_{s}^{\prime}\right) & 0\left(-M_{s s}^{\prime}\right) \\ M_{p s}\left(M_{p s}^{\prime}\right) & 0\left(-M_{s s}^{\prime}\right) & 0\left(-M_{s s}^{\prime}\right) & L_{s}\left(L_{s}^{\prime}\right)\end{array}\right]$ $L_{p}\left(L_{p}^{\prime}\right)=L_{m p}\left(L_{m p}^{\prime}\right)+L_{k p}, L_{s}\left(L_{s}^{\prime}\right)=L_{m s}\left(L_{m s}^{\prime}\right)+L_{k s}$.

3) Coupling effect on HV current: The currents in the HV side with the transformer before and after core integration are derived and shown in (14) and (15), respectively. Combine (12), (14) and (15), it can be found that the currents in the HV side keep constant when the three separate cores are integrated into one core. The same value of HV current and 


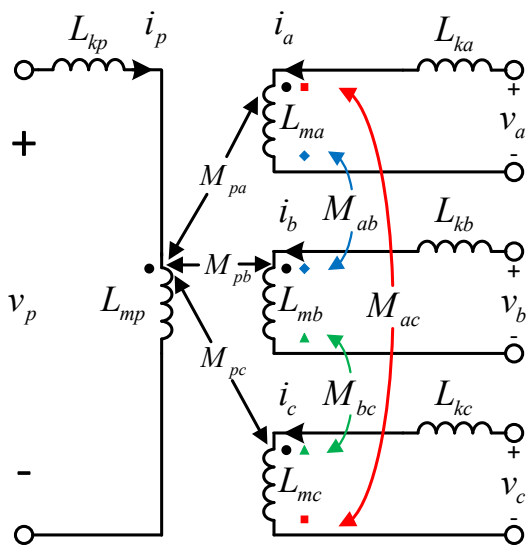

Fig. 8. The equivalent circuit of the proposed transformer.

terminal voltage mean the core integration will not affect the transmission power.

$$
\begin{gathered}
\frac{d i_{p}}{d t}=\frac{L_{s}}{L_{p} L_{s}-3 M_{p s}{ }^{2}} \cdot v_{p}+\frac{-M_{p s}}{L_{p} L_{s}-3 M_{p s}{ }^{2}} \cdot\left(v_{a}+v_{b}+v_{c}\right) \\
\frac{d i_{p}^{\prime}}{d t}=\frac{\left(L_{s}^{\prime}-2 M_{s s}^{\prime}\right)}{L_{p}^{\prime}\left(L_{s}^{\prime}-2 M_{s s}^{\prime}\right)-3 M_{p s}^{\prime}{ }^{2}} \cdot v_{p}+ \\
\frac{-M_{p s}^{\prime}}{L_{p}^{\prime}\left(L_{s}^{\prime}-2 M_{s s}^{\prime}\right)-3 M_{p s}^{\prime 2}} \cdot\left(v_{a}+v_{b}+v_{c}\right)
\end{gathered}
$$

4) Coupling effect on LV current: When the operation status of the three parallel modules are kept the same, i.e. $v_{a}=v_{b}=v_{c}=v_{s}$. The current slew rates of the LV side with the transformer before and after core integration are expressed in (16) and (17), respectively. Combine (12), (16) and (17), the currents in the LV side are also keep constant after core integration. Moreover, assume the initial currents of three modules are all 0 , and the same $d i / d t$ means the currents through three modules are balanced. And it is clear that the proposed solution can effectively decouple the three secondary windings, which only individually couple with the common primary winding, and therefore the integrated magnetic structure eventually behaves as three single-phase transformers.

$$
\begin{gathered}
\frac{d i_{a}}{d t}=\frac{d i_{b}}{d t}=\frac{d i_{c}}{d t}=\frac{-M_{p s}}{L_{p} L_{s}-3 M_{p s}{ }^{2}} \cdot v_{p}+\frac{L_{p}}{L_{p} L_{s}-3 M_{p s}{ }^{2}} \cdot v_{s}, \\
\frac{d i_{a}^{\prime}}{d t}=\frac{d i_{b}^{\prime}}{d t}=\frac{d i_{c}^{\prime}}{d t}=\frac{-M_{p s}^{\prime}}{L_{p}^{\prime}\left(L_{s}^{\prime}-2 M_{s s}^{\prime}\right)-3 M_{p s}^{\prime}{ }^{2}} \cdot v_{p}+ \\
\frac{L_{p}^{\prime}}{L_{p}^{\prime}\left(L_{s}^{\prime}-2 M_{s s}^{\prime}\right)-3 M_{p s}^{\prime}{ }^{2}} \cdot v_{s} .
\end{gathered}
$$

When introducing additional phase shift between parallel modules as studied in [9], for the transformer before core integration, (18) can be derived. It can be found that the currents though the parallel modules will be different due to the magnetizing currents. For the proposed integrated transformer,

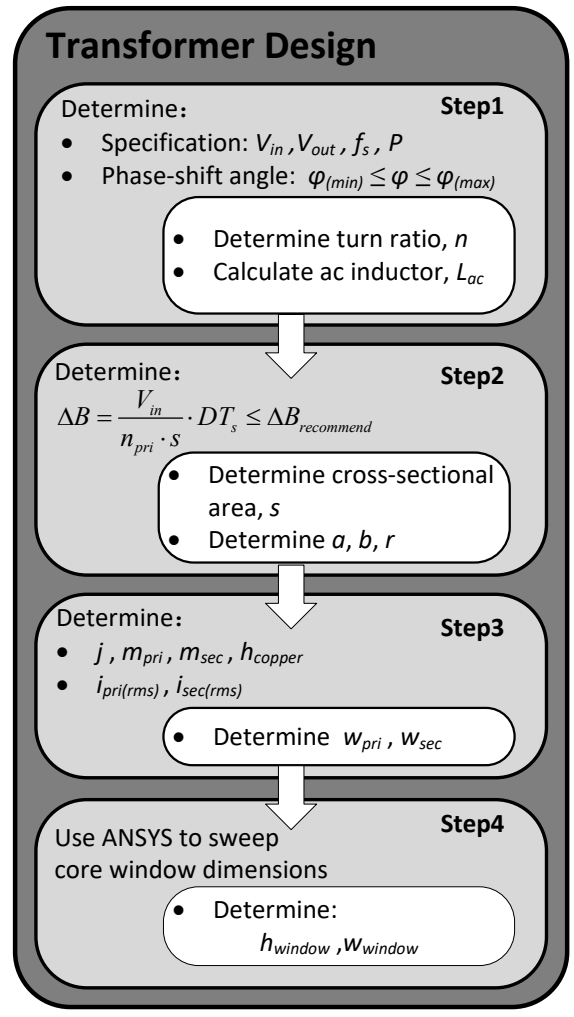

Fig. 9. Flowchart for transformer design.

(19) can be derived. The coupling between three LV windings will reduce the current discrepancy.

$$
\begin{gathered}
\frac{d i_{a}}{d t}-\frac{d i_{b}}{d t}=\frac{1}{L_{s}}\left(v_{a}-v_{b}\right) \\
\frac{d i_{a}}{d t}-\frac{d i_{c}}{d t}=\frac{1}{L_{s}}\left(v_{a}-v_{c}\right) \\
\frac{d i_{b}}{d t}-\frac{d i_{c}}{d t}=\frac{1}{L_{s}}\left(v_{b}-v_{c}\right) \\
\frac{d i_{a}^{\prime}}{d t}-\frac{d i_{b}^{\prime}}{d t}=\frac{1}{L_{s}^{\prime}+M_{s s}^{\prime}}\left(v_{a}-v_{b}\right) \\
\frac{d i_{a}^{\prime}}{d t}-\frac{d i_{c}^{\prime}}{d t}=\frac{1}{L_{s}^{\prime}+M_{s s}^{\prime}}\left(v_{a}-v_{c}\right) \\
\frac{d i_{b}^{\prime}}{d t}-\frac{d i_{c}^{\prime}}{d t}=\frac{1}{L_{s}^{\prime}+M_{s s}^{\prime}}\left(v_{b}-v_{c}\right)
\end{gathered}
$$

5) Summary: Even though the core integration will introduce the coupling between the LV windings, the transmission power still remains unchanged. When the operation status of the three parallel modules are kept the same, the proposed transformer is decoupled into three discrete transformers. Moreover, the coupling between LV windings is helpful for currents balancing.

\section{Transformer with integrated $L_{a c}$}

According to (7), in order to regulate the PPDAB in a certain power range, the inductance of $L_{a c}$ must be properly selected. Normally, external inductors are added to meet the regulation requirement. Based on the FEA results, it can be concluded that placing the primary and secondary windings on 


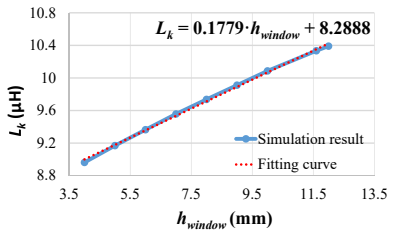

(a)

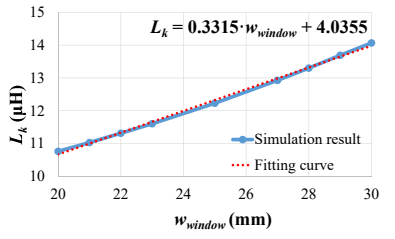

(b)
Fig. 10. Leakage inductance versus core dimensions. (a) The curve of leakage inductance versus $h_{\text {window }}$. (b) The curve of leakage inductance versus $w_{\text {window }}$.

the different core legs will lead to high leakage inductance. In order to ensure the leakage inductor is large enough to serve as the ac inductor in the PPDAB converter, the flowchart for transformer design is derived and shown in Fig. 9.

Step 1: According to (7), when the voltage of HV side and LV side are matched, the turn ratio of the transformer can be determined; then the requirement of $L_{a c}$ can be calculated with the allowed range of phase-shift angle.

Step 2: In order to reduce the core loss, $\Delta B$ must be limited. According to (8), (20) and (21), the radius of the center leg $r$, length $a$ and width $b$ of the cross-sectional area of the outer legs can be determined.

$$
\begin{gathered}
\Delta B=\frac{V_{i n}}{N_{P} \cdot s} \cdot 0.5 \cdot T_{s} \\
b=\sqrt{3} r
\end{gathered}
$$

Step 3: To reduce the winding loss, the current density $j$ must be limited. For a switching frequency of $1 \mathrm{MHz}$, the optimal copper thickness is $2 \mathrm{oz}(70 \mu \mathrm{m})$. Then, according to the numbers of parallel layers of the windings, the width of the primary windings and secondary windings can be calculated.

Step 4: The minimum length of the core window can be calculated. Consider the thickness and number of the PCBs, the minimum height of the core window can also be determined.

$$
\begin{array}{r}
w_{\text {window }(\min )}=\max \left[n_{\text {pri }} w_{\text {pri }}+2 \delta_{\text {pri }}+\left(n_{\text {pri }}-1\right) \sigma_{\text {pri }}\right. \\
\left.n_{\text {sec }} w_{s e c}+2 \delta_{s e c}+\left(n_{s e c}-1\right) \sigma_{s e c}\right]
\end{array}
$$

$$
h_{\text {window }(\min )}=n_{P C B} \cdot h_{P C B}
$$

When $h_{\text {window }}$ increases, meaning copper filling factor decreases, it leads to higher leakage inductance as shown in the curve in Fig. 10 (a). The leakage inductance of the transformer versus $w_{\text {window }}$ is also plotted in Fig. 10 (b). The increasing $w_{\text {window }}$ weakens the coupling between the primary and secondary windings which further increase the leakage inductance. According to the tendencies shown in Fig. 10 (a) and Fig. 10 (b), determine the core window dimensions for ensuring the leakage inductor of the transformer can serve as the $L_{a c}$ of the PPDAB converter.

\section{EXPERIMENTAL RESULTS}

In order to verify the proposed converter and its associated magnetic integration, a 1-MHz 400V/50V GaN-based PPDAB converter with the integrated transformers was constructed and tested. The implemented PPDAB converter is shown in Fig. 11 and the parameters of this prototype are summarized in Table IV. As it can be seen from Fig. 11, the converter consists of five parts including $\mathrm{HV} \mathrm{H}$-bridge, integrated planner transformers, LV H-bridges, LV base-board, and control board. In order to increase control precision, TMS320F28379D is adopted due to its 16 high-resolution PWM channels.

The core is custom made. In order to reduce the manufacture complexity, a set of the core are divided into six identical parts, as shown in Fig. 12 (a). Four double layers PCBs (two for primary windings and two for secondary windings) as shown in Fig. 12 (b) are utilized to reduce the intra-winding and interwinding capacitance. The top and bottom layers of each PCB are identical and connected in parallel. The primary windings are split and put onto two PCBs, PCB1 and PCB4, which are connected in series. The secondary windings are placed on PCB2 and PCB3, which are identical and connected in parallel for carrying high current.

The experimental waveforms of the proposed PPDAB converter working at one secondary winding shorted are shown in Fig. 13. Due to the short circuit connection, the magnetizing current of the shorted secondary winding will be zero. The results are able to verify that the magnetic coupling between the parallel modular units is negligible and the proposed integrated transformers are equivalent to three discrete transformers. In addition, another test on adding additional phase shift between the parallel LV H-bridges is implemented to show the currents balancing feature of the proposed integrated transformers and the test results are shown in Fig. 14. It can be seen, adding LV side phase shift will not affect the converter operation, which has the same performance as use three fully decoupled transformers.

Finally, the waveforms of the PPDAB converter operating at $1264 \mathrm{~W}, 400 \mathrm{~V} / 50 \mathrm{~V}$ are shown in Fig. 15. It shows that ZVS for switches on the both HV and LV sides can be achieved and the three high-frequency ac currents in the paralleled branches are balanced. The efficiency of proposed three-phase PPDAB converter is shown in Fig. 16. The peak efficiency is $97.51 \%$ at $842 \mathrm{~W}$. Under the peak-efficiency and full-load operation, the thermal figures are shown in Fig. 17. The temperatures of the $\mathrm{HV}$ switching device under these two operations are $61.4^{\circ} \mathrm{C}$ and $85.2^{\circ} \mathrm{C}$, respectively. The $\mathrm{LV}$ switching devices are block by LV based board. Hence, the temperature of LV switching devices has to be measured by multimeter with thermocouple. During the experiment, the temperature of the LV switching has been within the normal temperature range. And the losses breakdown of the converter is shown in Fig. 18 where the switching device loss is calculated from LTspice simulation, core loss is calculated from theoretical analysis, and the winding loss is calculated from the experimental result of ac resistance. All PCBs in the prototype are connected by many connectors, so the terminal loss should be also considered. However, the contact resistance is hard to be measured, thereby the terminal loss is estimated based on experience. 


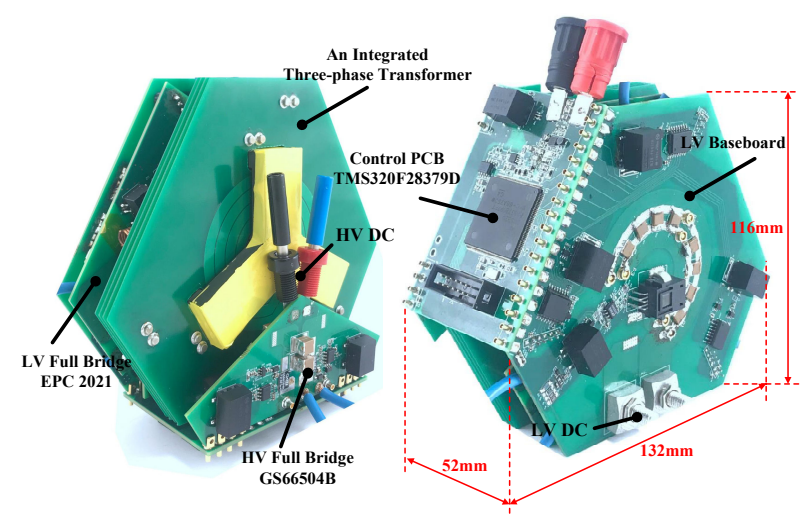

Fig. 11. Picture of the PPDAB hardware taken from different perspectives.

TABLE IV

TECHNICAL DETAILS OF THE PPDAB PROTOTYPE

\begin{tabular}{cccc}
\hline \hline Parameter & Value & Parameter & Value \\
\hline$V_{i n}$ & $400 \mathrm{~V}$ & $V_{\text {out }}$ & $50 \mathrm{~V}$ \\
$P$ & $1.2 \mathrm{~kW}$ & $f_{s}$ & $1 \mathrm{MHz}$ \\
Core's material & ML91S & Core's dimensions & U-37.5-12.2-18.5-NC \\
Turns-P,A,B,C & $8: 3: 3: 3$ & $L_{a c}$ & $10.58 \mu \mathrm{H}$ \\
$\varphi$ & 0.1 & $\varphi_{p 1}$ & 0.02 \\
$\varphi_{p 2}$ & 0.015 & Digital controller & TMS320F28379D \\
Switches on the HV side & GS66504B & Switches on the LV side & EPC2021 \\
\hline \hline
\end{tabular}

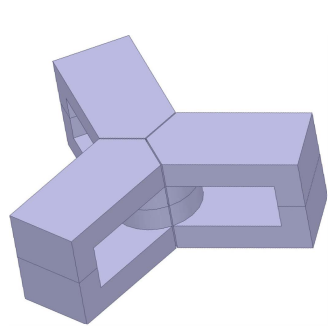

(a)

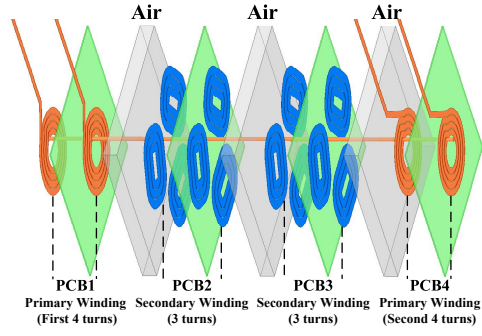

(b)
Fig. 12. The Planar transformer. (a) Split the proposed transformer into three pieces. (b) The structure of PCB windings.

\section{CONCLUSIONS}

In order to increase the current capability of the high voltage gain DAB converter in high-power applications, the PPDAB converter is proposed. The paralleled modular units in the LV side can reduce the current stress on the devices. However, the number of magnetic components increases. To achieve a more compact design, the GaN-based high frequency PPDAB converter with a new integrated transformer is proposed. Compared to other traditional solutions, the proposed transformer can obtain the lower winding loss while integrating the external inductor $L_{a c}$. The analysis of current balancing and the flowchart for transformer design are also provided. Finally, a $400 \mathrm{~V} / 50 \mathrm{~V}, 1-\mathrm{MHz}, 1.2-\mathrm{kW}$ PPDAB converter with the proposed magnetic structure and $\mathrm{GaN}$ transistors is designed, and a peak efficiency of $97.51 \%$ is achieved.

The proposed structure with the unique core shape integrates not only three transformers but also the ac inductor into one

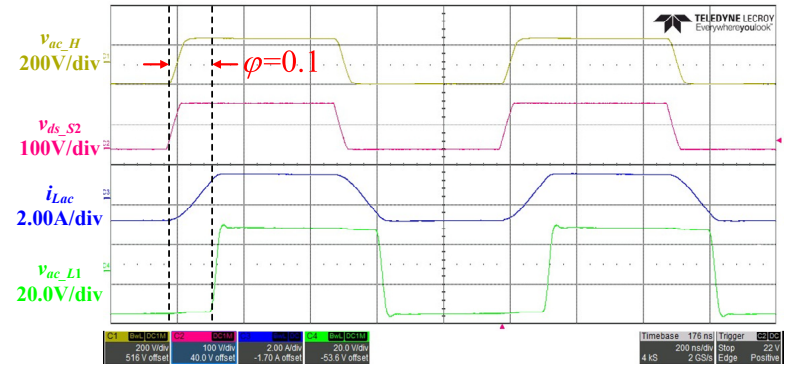

(a)

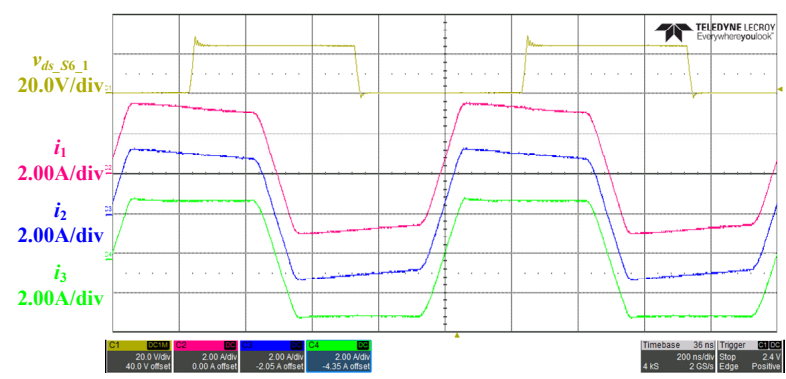

(b)

Fig. 13. Experimental waveforms @ one secondary winding shorted. (a) Waveforms of $v_{a c_{-} H}, v_{d s_{-} s 2}, i_{L_{a c}}$ and $v_{a c_{-} L 1}$. (b) Waveforms of $v_{d s_{-} s 6}$, $i_{1}, i_{2}$ and $i_{3}$.

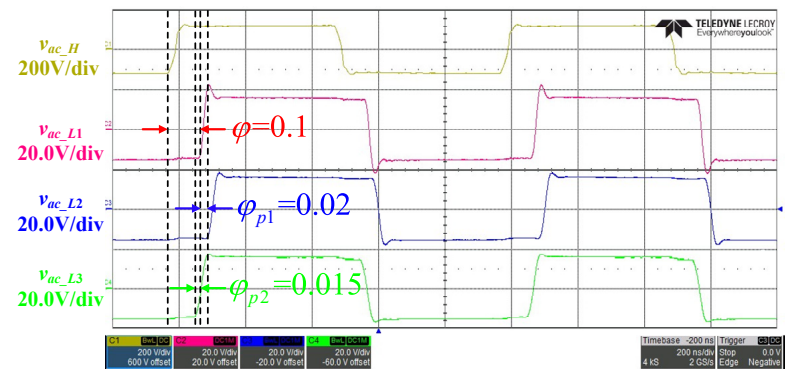

(a)

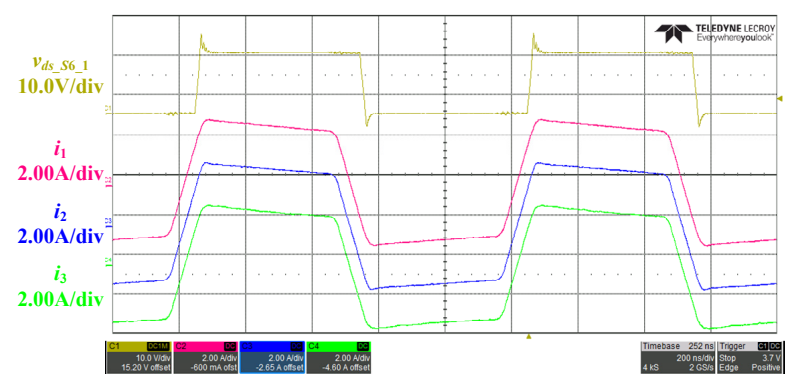

(b)

Fig. 14. Experimental waveforms @ additional phase shift between the parallel LV H-bridges are added. (a) Waveforms of $v_{a c_{-} H}, v_{a c_{-} L 1}$, $v_{a c_{-} L 2}$ and $v_{a c_{-} L 3}$. (b) Waveforms of $v_{d s_{-} s 6}, i_{1}, i_{2}$ and $i_{3}$.

magnetic component so that the volume of the converter is further reduced. Moreover, the winding loss can be reduced accordingly with the proposed magnetic integration method due to the less winding mean length. However, there are still some design challenges existing, for example, the large external magnetic field may cause EMI problems, and accurate calculation on leakage inductance. Therefore, modeling the 


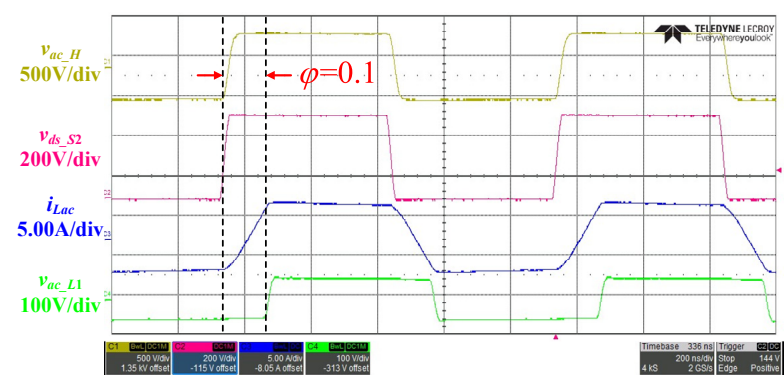

(a)

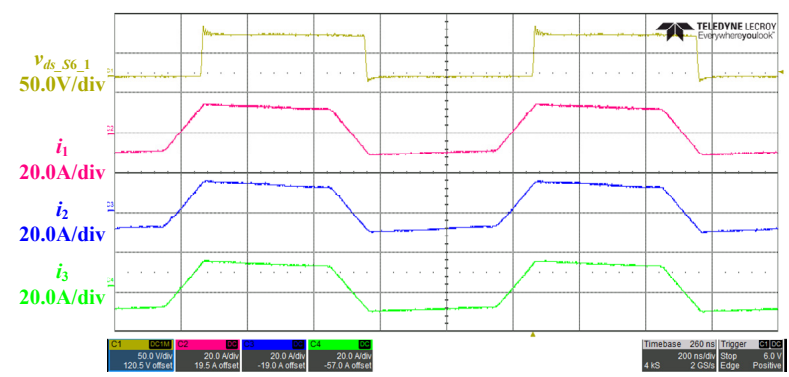

(b)

Fig. 15. Experimental waveforms $@ V_{\text {in }}=400 \mathrm{~V}, V_{\text {out }}=50 \mathrm{~V}, \varphi=0.1$. (a) Waveforms of $v_{a c_{-} H}, v_{d s_{s} s 2}, i_{L_{a c}}$ and $v_{a c_{-} L 1}$. (b) Waveforms of $v_{d s_{-} s 6}, i_{1}, i_{2}$ and $i_{3}$.

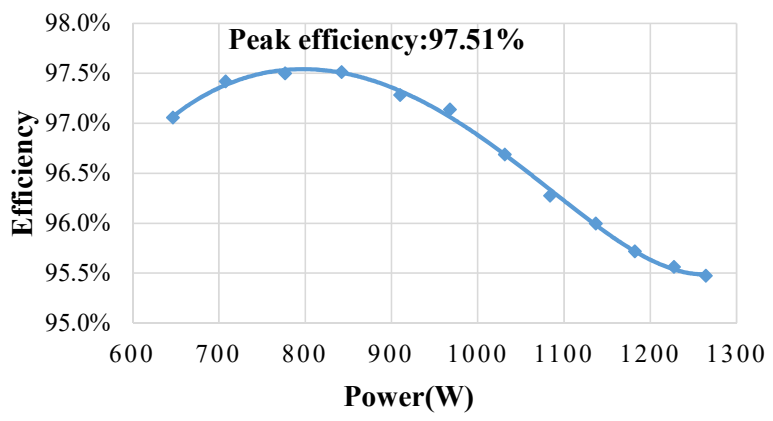

Fig. 16. Measured efficiency.

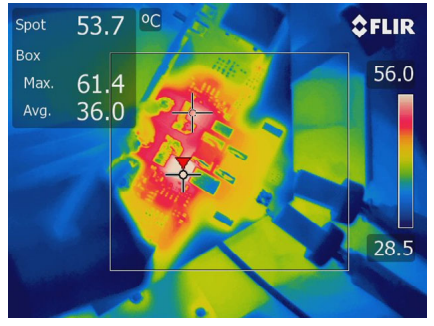

(a)

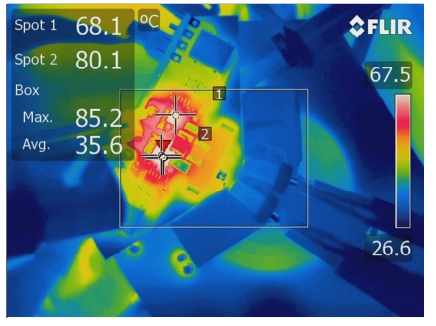

(b)
Fig. 17. The thermal figure. (a) Peak-efficiency operation. (b) Full-load operation.

leakage inductance, winding loss and suppressing the EMI issues will be carried out in the future work.

\section{REFERENCES}

[1] S. Vazquez, S. M. Lukic, E. Galvan, L. G. Franquelo, and J. M. Carrasco, "Energy storage systems for transport and grid applica-

\section{Losses breakdown}

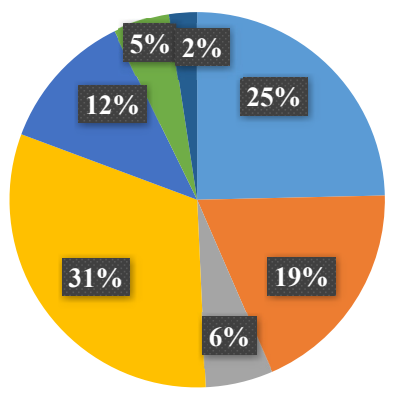

HV Switching Device Loss

LV Switching Device Loss

Core Loss

Winding Loss

- Terminal Loss

Input and Output Capacitor

Loss

Fig. 18. Losses breakdown.

tions," IEEE Transactions on Industrial Electronics, vol. 57, DOI 10.1109/TIE.2010.2076414, no. 12, pp. 3881-3895, Dec. 2010.

[2] F. Xue, R. Yu, and A. Q. Huang, "A $98.3 \%$ efficient gan isolated bidirectional dcâdc converter for dc microgrid energy storage system applications," IEEE Transactions on Industrial Electronics, vol. 64, DOI 10.1109/TIE.2017.2686307, no. 11, pp. 9094-9103, Nov. 2017.

[3] Z. Chen, J. M. Guerrero, and F. Blaabjerg, "A review of the state of the art of power electronics for wind turbines," IEEE Transactions on Power Electronics, vol. 24, DOI 10.1109/TPEL.2009.2017082, no. 8, pp. 1859-1875, Aug. 2009.

[4] B. Zhao, Q. Song, W. Liu, and Y. Sun, "Overview of dual-active-bridge isolated bidirectional dcâdc converter for high-frequency-link powerconversion system," IEEE Transactions on Power Electronics, vol. 29, DOI 10.1109/TPEL.2013.2289913, no. 8, pp. 4091-4106, Aug. 2014.

[5] Z. Zhang, Y. Cai, Y. Zhang, D. Gu, and Y. Liu, "A distributed architecture based on microbank modules with self-reconfiguration control to improve the energy efficiency in the battery energy storage system," IEEE Transactions on Power Electronics, vol. 31, DOI 10.1109/TPEL.2015.2406773, no. 1, pp. 304-317, Jan. 2016.

[6] S. P. Engel, M. Stieneker, N. Soltau, S. Rabiee, H. Stagge, and R. W. De Doncker, "Comparison of the modular multilevel dc converter and the dual-active bridge converter for power conversion in hvdc and mvdc grids," IEEE Transactions on Power Electronics, vol. 30, DOI 10.1109/TPEL.2014.2310656, no. 1, pp. 124-137, Jan. 2015.

[7] W. Song, N. Hou, and M. Wu, "Virtual direct power control scheme of dual active bridge dcâdc converters for fast dynamic response," IEEE Transactions on Power Electronics, vol. 33, no. 2, pp. 1750-1759, 2018.

[8] N. Hou, W. Song, and M. Wu, "Minimum-current-stress scheme of dual active bridge dcâdc converter with unified phase-shift control," IEEE Transactions on Power Electronics, vol. 31, no. 12, pp. 8552-8561, 2016.

[9] Z. Zhang, K. Tomas-Manez, Y. Xiao, and M. A. E. Andersen, "High voltage gain dual active bridge converter with an extended operation range for renewable energy systems," in 2018 IEEE Applied Power Electronics Conference and Exposition (APEC), DOI 10.1109/APEC.2018.8341271, pp. 1865-1870, Mar. 2018.

[10] B. Zhao, Q. Yu, and W. Sun, "Extended-phase-shift control of isolated bidirectional dcâdc converter for power distribution in microgrid," IEEE Transactions on Power Electronics, vol. 27, DOI 10.1109/TPEL.2011.2180928, no. 11, pp. 4667-4680, Nov. 2012.

[11] Y. Cho, W. Cha, J. Kwon, and B. Kwon, "High-efficiency bidirectional dab inverter using a novel hybrid modulation for stand-alone power generating system with low input voltage," IEEE Transactions on Power Electronics, vol. 31, DOI 10.1109/TPEL.2015.2476336, no. 6, pp. 41384147, Jun. 2016.

[12] B. Zhao, Q. Song, and W. Liu, "Efficiency characterization and optimization of isolated bidirectional dcâdc converter based on dual-phase-shift control for de distribution application," IEEE Transactions on Power Electronics, vol. 28, DOI 10.1109/TPEL.2012.2210563, no. 4, pp. 17111727, Apr. 2013.

[13] K. Wu, C. W. de Silva, and W. G. Dunford, "Stability analysis of isolated bidirectional dual active full-bridge dcâdc converter with triple phaseshift control," IEEE Transactions on Power Electronics, vol. 27, DOI 10.1109/TPEL.2011.2167243, no. 4, pp. 2007-2017, Apr. 2012.

[14] A. Tong, L. Hang, G. Li, X. Jiang, and S. Gao, "Modeling and analysis of a dual-active-bridge-isolated bidirectional $\mathrm{dc} / \mathrm{dc}$ converter to minimize 
rms current with whole operating range," IEEE Transactions on Power Electronics, vol. 33, DOI 10.1109/TPEL.2017.2692276, no. 6, pp. 53025316, Jun. 2018.

[15] R. Ramachandran and M. Nymand, "Experimental demonstration of a 98.8\% efficient isolated dcâdc gan converter," IEEE Transactions on Industrial Electronics, vol. 64, DOI 10.1109/TIE.2016.2613930, no. 11, pp. 9104-9113, Nov. 2017.

[16] H. Akagi, S. Kinouchi, and Y. Miyazaki, "Bidirectional isolated dualactive-bridge (dab) dc-dc converters using 1.2-kv 400-a sic-mosfet dual modules," CPSS Transactions on Power Electronics and Applications, vol. 1, DOI 10.24295/CPSSTPEA.2016.00004, no. 1, pp. 33-40, Dec. 2016.

[17] L. F. Costa, G. Buticchi, and M. Liserre, "Optimum design of a multipleactive-bridge dcâdc converter for smart transformer," IEEE Transactions on Power Electronics, vol. 33, DOI 10.1109/TPEL.2018.2799680, no. 12 , pp. $10112-10121$, Dec. 2018.

[18] L. F. Costa, F. Hoffmann, G. Buticchi, and M. Liserre, "Comparative analysis of multiple active bridge converters configurations in modular smart transformer,' IEEE Transactions on Industrial Electronics, vol. 66 , DOI 10.1109/TIE.2018.2818658, no. 1, pp. 191-202, Jan. 2019.

[19] B. Li, Q. Li, F. C. Lee, Z. Liu, and Y. Yang, "A high-efficiency highdensity wide-bandgap device-based bidirectional on-board charger,' IEEE Journal of Emerging and Selected Topics in Power Electronics, vol. 6, DOI 10.1109/JESTPE.2018.2845846, no. 3, pp. 1627-1636, Sep. 2018.

[20] Y. Du, A. Q. Huang, F. Xue, and R. Yu, "A modular integrated li-ion battery pack with a multi-core based transformer isolated bidirectional dc-dc converter," in 2014 16th European Conference on Power Electronics and Applications, pp. 1-10, 2014.

[21] B. Zhao, Q. Song, J. Li, Y. Wang, and W. Liu, "Modular multilevel high-frequency-link dc transformer based on dual active phase-shift principle for medium-voltage dc power distribution application," IEEE Transactions on Power Electronics, vol. 32, no. 3, pp. 1779-1791, 2017.

[22] H. Li, S. Munk-Nielsen, X. Wang, R. Maheshwari, S. BÄczkowski, C. Uhrenfeldt, and W. . Franke, "Influences of device and circuit mismatches on paralleling silicon carbide mosfets," IEEE Transactions on Power Electronics, vol. 31, DOI 10.1109/TPEL.2015.2408054, no. 1 , pp. 621-634, Jan. 2016

[23] S. Gao, Y. Wang, Y. Guan, and D. Xu, "A high step up sepic-based converter based on partly interleaved transformer," IEEE Transactions on Industrial Electronics, vol. 67, DOI 10.1109/TIE.2019.2910044, no. 2 , pp. 1455-1465, Feb. 2020.

[24] Y. Guan, Y. Wang, D. Xu, and W. Wang, "A $1 \mathrm{mhz}$ half-bridge resonant dc/dc converter based on gan fets and planar magnetics," IEEE Transactions on Power Electronics, vol. 32, DOI 10.1109/TPEL.2016.2579660, no. 4, pp. 2876-2891, Apr. 2017.

[25] Y. Wang, S. Gao, and D. Xu, "A 1-mhz-modified sepic with zvs characteristic and low-voltage stress," IEEE Transactions on Industrial Electronics, vol. 66, DOI 10.1109/TIE.2018.2851974, no. 5, pp. 3422 3426, May. 2019.

[26] Y. Guan, Y. Wang, W. Wang, and D. Xu, "A high-performance isolated high-frequency converter with optimal switch impedance," IEEE Transactions on Industrial Electronics, vol. 66, DOI 10.1109/TIE.2018.2868031, no. 7, pp. 5165-5176, Jul. 2019.

[27] Y. Guan, Y. Wang, W. Wang, and D. Xu, "A high-frequency clcl converter based on leakage inductance and variable width winding planar magnetics," IEEE Transactions on Industrial Electronics, vol. 65, DOI 10.1109/TIE.2017.2716878, no. 1, pp. 280-290, Jan. 2018.

[28] C. Fei, R. Gadelrab, Q. Li, and F. C. Lee, "High-frequency three-phase interleaved llc resonant converter with gan devices and integrated planar magnetics," IEEE Journal of Emerging and Selected Topics in Power Electronics, vol. 7, DOI 10.1109/JESTPE.2019.2891317, no. 2, pp. 653663, Jun. 2019

[29] R. Chattopadhyay, M. A. Juds, P. R. Ohodnicki, and S. Bhattacharya, "Modelling, design and analysis of three limb high frequency transformer including transformer parasitics, for sic mosfet based three port dab," in IECON 2016 - 42nd Annual Conference of the IEEE Industrial Electronics Society, DOI 10.1109/IECON.2016.7793593, pp. 4181-4186, Oct. 2016
[30] P. L. Dowell, "Effects of eddy currents in transformer windings," Proceedings of the Institution of Electrical Engineers, vol. 113, DOI 10.1049/piee.1966.0236, no. 8, pp. 1387-1394, Aug. 1966.

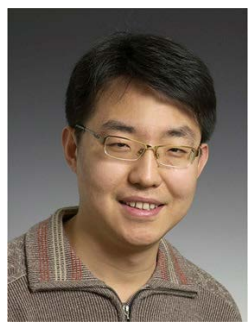

Zhe Zhang (M'11-SM'16) received the B.Sc. and M.Sc. degrees in power electronics from Yanshan University, Qinhuangdao, China, in 2002 and 2005, respectively, and the PhD degree from the Technical University of Denmark, Kgs. Lyngby, Denmark, in 2010.

$\mathrm{He}$ is currently an Associate Professor in the Department of Electrical Engineering, at the Technical University of Denmark (DTU). Since Jan. 2018, he has been the Head of Studies in charge of Electrical Engineering MSc Programme at DTU. From 2005 to 2007, he was an Assistant Professor at Yanshan University. From June 2010 to August 2010, he was with the University of California, Irvine, CA, USA, as a visiting scholar. He was an Assistant Professor at the Technical University of Denmark during 2011 and 2014. He has authored or co-authored more than 150 transactions and international conference papers and filed over ten patent applications. He has supervised over ten PhD students since 2013.

Dr. Zhang's current research interests include applications of wide bandgap devices, high frequency dc-dc converters, multiple-input dcdc converters, soft-switching power converters and multi-level dc-ac inverters for renewable energy systems (RES), hybrid electric vehicles (HEV) and uninterruptable power supplies (UPS); piezoelectric-actuator and piezoelectric-transformer based power conversion systems.

Dr. Zhang has received several awards and honors including Best Paper Awards in IEEE ECCE, IFEEC, IGBSG, Best Teacher of the Semester, Chinese Government Award for Outstanding Students Abroad, etc. He is also a guest Associate Editor in IEEE Transactions on Industrial Electronics, Associate Editor in IEEE Journal of Emerging and Selected Topics in Power Electronics, Associate Editor of IEEE Access and guest Editor of IEEE Journal of Emerging and Selected Topics in Industrial Electronics.

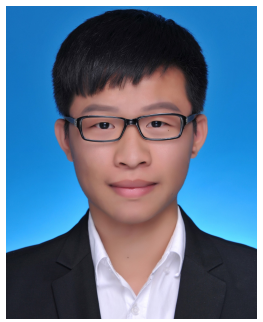

Jiasheng Huang received the B.S. degree in electrical engineering from Fuzhou University, Fuzhou, China, in 2017. He is currently working toward the M.S. degree in electrical engineering at School of Electrical Engineering, Xi'an Jiaotong University, Xi'an, China.

His research interests include high-frequency power conversion, high-frequency magnetic design, and application of wide-band-gap devices.

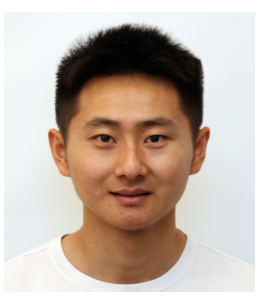

Yudi Xiao received the B.Sc. and M.Sc. degrees in power electronics from Fuzhou University, Fuzhou, China, in 2015 and 2018, respectively. $\mathrm{He}$ is currently an industrial PhD student with the Department of Electrical Engineering, Technical University of Denmark and Welltec A/S.

His research interests include soft-switching power converters, design automation for power electronics, and high temperature electronics for downhole applications. 